\title{
O DESIGN BRASILEIRO NO CENÁRIO INTERNACIONAL A participação brasileira no prêmio if Design Award
}

\author{
BRAZILIAN DESIGN IN THE INTERNATIONAL SCENE \\ The Brazilian participation in the iF Design Award
}

\author{
Centro Brasil Design \\ anabrum@cbd.org.br \\ Buso, Juliana Mascaro \\ Centro Brasil Design \\ juliana@cbd.org.br \\ Gaziri, Leticia Castro \\ Centro Brasil Design \\ leticia@cbd.org.br
}

Gouveia, Ana Leocadia de Souza Brum Donikian

\begin{abstract}
Resumo: Os prêmios internacionais de design tem a importante função de fortalecer a reputação dos designers premiados, são uma forma de proteção do trabalho inscrito, certificam projetos de forma idônea além de dar credibilidade e visibilidade aos premiados. É apresentada aqui a importância da participação em prêmios, o funcionamento da dinâmica do júri do iF Design Award (iF - International Forum) e a participação brasileira no prêmio que é um dos mais tradicionais e mais completos prêmios de design em âmbito mundial. Os projetos brasileiros tem ganhado destaque na premiação e a participação acontece em maior número desde 2004, atualmente percebe-se que existe a cultura de participação em premiações internacionais nas empresas brasileiras.
\end{abstract}

Palavras-chave: design brasileiro, competitividade e prêmios de design

\begin{abstract}
The international design awards has the important function to strength the reputation of the awarded winners designers, it is a form of protection of the submitted entry, certifies projects in an appropriate way besides it gives credibility and visibility to the winners. It is presented here the importance of the participation in awards such as the dynamics of the if Design Award jury section (iF - International Forum), the Brazilian participation in the prize that is one of the most traditional and most complete design awards worldwide. The Brazilian projects have been on Stoplight in the design awards and featured on Brazilian participation happens in a great number since 2004, today we can see that there is a
\end{abstract}


culture of Brazilian companies that participate in international design awards.

Keywords: Brazilian design, competitiveness and design awards

\section{INTRODUÇÃO}

Novos produtos, embalagens e a intensa produção da indústria da comunicação movimentam grande parte da economia mundial, pois impulsionam a inovação, a inserção de novas tecnologias, a abertura de novos mercados e o aumento nas vendas, ampliando a competitividade global que hoje está cada vez mais acirrada.

Neste contexto, o design é uma importante ferramenta de diferencial competitivo entre os produtos colocados no mercado para um consumidor final cada vez mais exigente. Uma medida do desempenho do design é a utilização de prêmios e outros tipos de avaliação dos pares (MOZOTA, 2011, p. 236). Os prêmios de design atestam o bom design do produto, certificam a qualidade dos mesmos e abrem espaço de destaque no mercado para os premiados.

Segundo a pesquisa Focusing on design boosts sales divulgada pelo German Design Council (2012, p.10) prêmios de design transmitem expertise em design e as corporações com um forte foco em design usam prêmios de forma estratégica. Um prêmio de design impacta positivamente na imagem da empresa e seguramente ajuda nas vantagens competitivas.

Hoje existem no mundo cinco prêmios de maior relevância no setor de design. São eles iF Design Award, o Red Dot Design Award (ambos com sede na Alemanha), o Idea International Design Award, o Good Design (ambos com sede nos Estados Unidos) e o Good Design (com sede no Japão). Os dois últimos apesar de usarem a mesma nomenclatura são diferentes premiações e coordenados por diferentes instituições.

Segundo Fontoura (2006), participar de concursos de design é, portanto, uma forma de integrar-se ao processo de industrialização. É, também, uma excelente oportunidade de participar do aquecimento do processo produtivo e da comercialização dos bens de capital e de consumo pela sociedade. Em outras palavras, significa participar ativamente do processo de desenvolvimento do país.

A partir do levantamento dos prêmios de maior relevância e mais disputados internacionalmente, foi identificado no if Design Award um dos selos internacionais mais valorizados comercialmente em âmbito mundial, além de ser o prêmio mais antigo do setor que acontece ininterruptamente desde 1953, tem caráter comercial e uma forte base industrial. O processo do júri é transparente, coerente e tem credibilidade, além do painel de jurados ser renovado a cada ano.

A conquista de uma chancela de qualidade internacional de design, além de prospectar negócios em outros países, pode trazer reflexos para o mercado interno. Moraes (1999) defende a abrangência global das iniciativas: "se considerarmos o design um instrumento capaz de contribuir para a indústria no que diz respeito à competitividade internacional e como elemento diferenciador na qualidade dos produtos industriais, não podemos enxergar nesta atividade uma referência somente regional ou periférica: ela é um instrumento capaz de alargar a competitividade das empresas em nível global" (MORAES, 1999 p.89). 
O objetivo deste artigo é mostrar como o design brasileiro tem conquistado espaço no mercado internacional por meio de premiações de um dos mais reconhecidos e tradicionais selos de qualidade internacional em design, o if Design Award. Trata-se também da importância da participação em prêmios de design referenciados, o funcionamento do júri, os benefícios oferecidos para os premiados, a cultura criada pelas empresas brasileiras de participação em prêmios internacionais e a participação brasileira no cenário internacional, mais especificamente no prêmio if Design Award.

\section{PRÊMIOS DE DESIGN}

Segundo o relatório A comparative look at design competitions divulgado pelo iF International Forum Design (2006, p.04), há 10 questões que ajudam a medir a importância de um prêmio de design:

\begin{tabular}{|l|l|}
\hline Critérios & Questionamento \\
\hline Reconhecimento & $\begin{array}{l}\text { Como é o posicionamento do prêmio comparado aos } \\
\text { concorrentes? }\end{array}$ \\
\hline Frequência & Quantas edições já ocorreram? \\
\hline Abrangência & $\begin{array}{l}\text { Existe um amplo espectro de categorias para atender as } \\
\text { variadas segmentações do design? }\end{array}$ \\
\hline Concorrentes & Qual o número de inscrições submetidas? \\
\hline Alcance & A concorrência é local, nacional ou internacional? \\
\hline Custos & $\begin{array}{l}\text { Quais os custos cobrados? O custo versus benefício vale a } \\
\text { pena? }\end{array}$ \\
\hline Júri & $\begin{array}{l}\text { Como funciona o painel dos jurados? O júri é internacional? } \\
\text { j painel de jurados é trocado todo ano? Quem são os } \\
\text { jurados? }\end{array}$ \\
\hline Exposição & $\begin{array}{l}\text { O prêmio dá visibilidade aos premiados? A quem chegam às } \\
\text { informações? Qual é o número de visitantes na exposição? }\end{array}$ \\
\hline Registro & Existe uma publicação? Qual a quantidade de acessos? \\
\hline Comunicação & Quais os benefícios prometidos pelo organizador? \\
\hline
\end{tabular}

Quadro 01 - questionamentos para a participação em prêmios internacionais.

Fonte: adaptado de iF Design Award (2014) - tradução livre do autor.

Todos estes critérios citados e pontuados no quadro 01 ajudam as empresas a terem uma visão geral de uma premiação. Como comentado por Fontoura (2006, p.199) no universo do trabalho internacionalizado, a competitividade e a busca de qualidade total são as principais características. Cada vez mais, as empresas procuram obter certificações, entre outras, a série ISO 9000.

(1996 apud BORGES 1996 p.183) faz um relato sobre suas reflexões acerca da participação em premiações: "para mim, o prêmio funciona como uma espécie de relógio interno, um momento em que eu paro e me pergunto: produzi algo este ano que mereça ser avaliado? Cadê minhas ideias? Continuo comprometido com os princípios que fundamentaram meu trabalho?". Os prêmios chancelam a qualidade do design da peça inscrita, pois na maioria dos casos os jurados são especialistas nas categorias que estão avaliando, como comentado no item 3 sobre a avaliação dos jurados no iF Design Award. 


\section{DINÂMICA DO JÚRI}

O iF Design Award teve sua primeira edição em 1953 com o foco no design de produtos. Hoje, além de produto, abrange a área de comunicação, embalagem, arquitetura e conceitos profissionais. O iF Design Award tem a maior participação de inscrições de estudantes do mundo com cerca de 15 mil inscritos vindos de diversos continentes. Entre as disciplinas contempladas na premiação é possível abranger variados segmentos, de tratores e veículos esportivos a luminárias, de embalagens de brinquedos a máquinas fotográficas, de cadeiras e camas a bicicletas, de utensílios de cozinha a produtos cirúrgicos, de livros a folders, de páginas na web a aplicativos e campanhas publicitárias.

Segundo GOUVEIA (2011, p.90) o prêmio if Design Award possui um júri internacional renomado e utiliza como critérios de validação: o produto no mercado tendo sido desenvolvido há no máximo dois anos, caracterizando o cunho industrial da premiação.

O processo do júri é transparente e tem credibilidade, todos os anos os jurados são renovados, vindos de variados países e o equilíbrio entre os gêneros também é considerado. Todos os anos são premiados um grande número de projetos, na edição de 2014, por exemplo, foram 4.615 projetos inscritos de 55 diferentes países, destes, 1.626 projetos foram selecionados. Os projetos foram avaliados durante três dias por 49 especialistas. Outro importante critério são os projetos estarem no mercado ou serem lançados no ano vigente da premiação e todos os projetos devem possuir design original.

Os jurados são divididos em suas categorias de expertise, sempre em grupos de três e a avaliação dos projetos é baseada na discussão entre os jurados que compõe o grupo. Em cada grupo ficam dois mediadores da equipe do iF Design Award para auxiliar e conduzir os jurados no que for necessário, além de controlar o tempo de julgamento de cada projeto submetido, para que sejam julgados e discutidos todos os projetos da categoria. Normalmente um grupo de jurados é responsável por avaliar duas categorias, ambas de sua expertise. A equipe do if que acompanha e conduz os jurados durante os três dias de avaliação é responsável pela anotação sobre a decisão dos jurados: "in" que significa que o projeto foi premiado em comum acordo, "out" que significa que o projeto não foi premiado e "maybe" que significa que os jurados estão na dúvida e voltam a julgar o projeto novamente após o término da vistoria de todos os projetos da categoria. É importante destacar que a decisão do júri é soberana e a equipe não tem influência nenhuma na decisão. Quando os jurados terminam de avaliar todos os projetos, a equipe do if Design Award que os acompanha volta nas etiquetas marcadas com o selo "maybe" e novamente discutem sobre o projeto em questão e decidem se o projeto será premiado ou não.

Após todos os projetos serem julgados e marcados com as etiquetas "in" ou "out", acontece o veto round, ou seja, cada jurado recebe duas bandeiras pretas com as suas iniciais e eles podem discordar da decisão do grupo que foi escalado para julgar aquela determinada categoria. No veto round os jurados podem discordar da decisão de qualquer outro jurado de qualquer categoria. Para balancear o processo existe 0 presidente do júri.

Após as marcações, a equipe do iF Design Award reúne os projetos marcados com as bandeiras pretas e o jurado com as iniciais na bandeira precisa defender 0 projeto para os outros colegas que fazem parte do corpo de jurados. O veto pode ser 
considerado para projetos premiados ou não premiados, significa que um dos jurados discorda da decisão do grupo. Após a defesa, o grupo que julgou o projeto faz uma contestação e a decisão final é feita pelo voto em consenso dos jurados. Esse processo é conduzido pelo presidente do júri e em caso de empate a decisão final é dele.

Após o veto round, acontece a seção if Gold Award, onde cada jurado recebe uma etiqueta dourada e marca o projeto que ele considera destaque e que merece ganhar o prêmio máximo do iF Design Award, o troféu if Gold Award. O troféu é concedido a 50 projetos.

Os projetos premiados podem usar o selo de excelência em design do if Design Award por tempo indeterminado. Algumas empresas usam o selo em anúncios e aproveitam a chancela de forma estratégica, como ilustrado na figura 1.

Figura 1: exemplo do uso do selo do if Design Award em anúncio de revista.

Fonte: Site Kia

\section{PARTICIPAÇÃO BRASILEIRA NO iF DESIGN AWARD}

O gráfico mostra o número de projetos brasileiros inscritos e premiados no if Design Award da edição 2004 até 2014 e abrange as disciplinas de produto, novos materiais, embalagens e peças de comunicação.

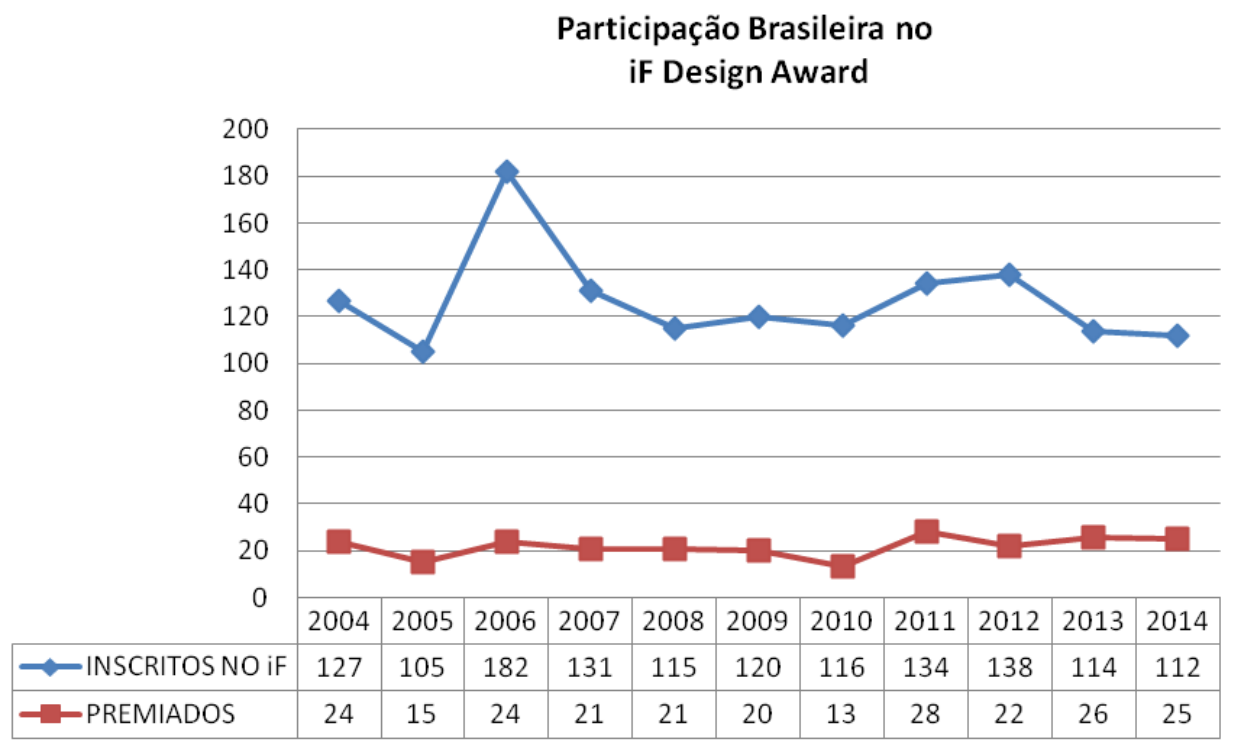

Gráfico 01: Participação Brasileira no iF Design Award

Fonte: "Elaborado pelo autor, com base na pesquisa realizada" 
Entre as edições de 2004 até 2012 as empresas brasileiras tiveram o apoio do programa Design Excellence Brazil ${ }^{1}$ para a participação no if Design Award. A participação no programa foi coordenada pelo Centro Brasil Design entre os anos 2008 e 2012 e entre 2004 e 2007, pela Câmara Brasil-Alemanha.

Durante a vigência do programa a iniciativa foi do Ministério do Desenvolvimento, Indústria e Comércio Exterior (MDIC), teve patrocínio da Agência Brasileira de Promoção de Exportações e Investimentos (Apex-Brasil), do Serviço Brasileiro de Apoio às Micro e Pequenas Empresas (SEBRAE) e da Agência Brasileira de Desenvolvimento Industrial ( $A B D I)$. Os patrocinadores citados aportaram recursos em diferentes edições do programa.

O lançamento aconteceu em junho de 2003, com a missão de promover o reconhecimento internacional do design de produtos e serviços desenvolvidos no país, com vistas ao fortalecimento da Marca Brasil e da imagem do produto brasileiro de maior valor agregado no exterior. O Design Excellence Brazil teve o intuito de fortalecer internamente a imagem nacional de produtor de bens de classe mundial.

Com o projeto Design Excellence Brazil foi possível estimular e apoiar a participação de projetos brasileiros no iF Design Award, na disciplina de produto e no prêmio de estudantes. Esse foi um importante caminho para a promoção da imagem do Brasil no exterior, além de proporcionar a abertura de novas possibilidades de negócios nos mercados internacionais.

Durante seus anos de atuação, o programa recebeu um total de 3.408 inscrições para a pré-seletiva nacional, das quais 1.679 produtos e projetos foram selecionados por comitês seletivos do programa para concorrer ao if Product Design Award com apoio técnico, logístico, financeiro e de mídia.

Nesse período, os brasileiros finalistas apoiados pelo programa foram 992. Destes, 179 foram premiados e receberam o selo if, dentre os premiados 9 receberam o troféu if Gold Award. Acredita-se que a ação tenha incitado um efeito multiplicador, estimulando a participação espontânea de designers e empresas brasileiras nessa e outras premiações internacionais.

O programa levou ao mundo a criatividade e a qualidade do design brasileiro, ampliando a visibilidade dos produtos e o fortalecimento da imagem do país. Anualmente eram selecionados 100 produtos brasileiros de reconhecido design, com critérios pré-estabelecidos, organizando desta forma um grupo de produtos de excelência capazes de representar o país, tanto internamente, como no exterior. A busca dos empresários em fazer parte deste grupo seleto de empresas incentivou a indústria nacional a, cada vez mais, se qualificar e buscar melhorar seus produtos.

De acordo com FERRAZ, J.C. et al (1995, p.8), "O padrão de concorrência é a variável que determina o resultado da competitividade". Um selo de um concurso de design profissional internacional eleva o padrão da indústria nacional e faz com que haja o interesse da parte dos empresários em investir em novos produtos para competir em excelência, tecnologia e criatividade. Além de valorizar o produto, os selos proporcionam uma valorização das equipes envolvidas no projeto.

O autor ainda afirma que: "seriam competitivas as firmas que a cada instante adotassem estratégias competitivas mais adequadas ao padrão de concorrência

\footnotetext{
1 Programa Design \&Excellence Brazil: atuou, entre 2004 e 2012, com o objetivo de promover o design brasileiro no exterior por meio da participação em prêmios internacionais de design, em especial, o iF Design Award.
} 
setorial". Os prêmios avaliam os produtos inscritos por categoria e as empresas inscritas, após a decisão final do júri, têm acesso aos produtos concorrentes premiados por segmento industrial.

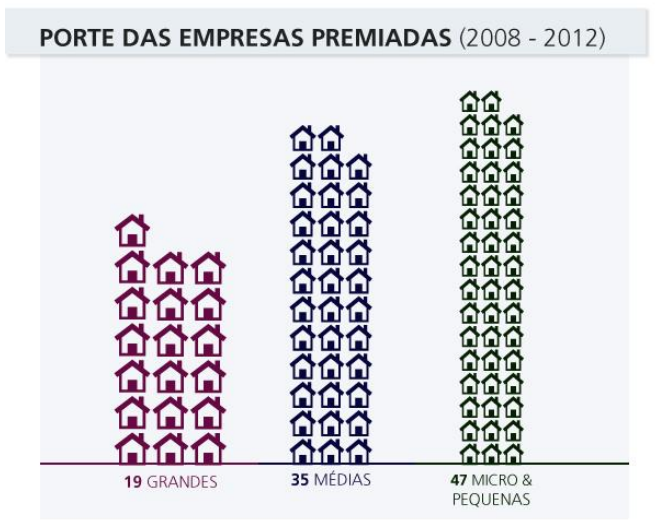

Gráfico 02: Infográfico - Porte das Empresas Premiadas (2008 - 2012).

Fonte: "Elaborado pelo autor, com base na pesquisa realizada"

De acordo com o infográfico acima, considerando o porte das empresas, o maior número de premiados está entre as micro e pequenas empresas e as médias empresas, com mais de $80 \%$ das empresas premiadas, entre 2008 e 2012 . Isso mostra que as micro e pequenas empresas e as empresas de médio porte são as que apresentam maior capacidade de inovar pelo design. Usam o design como uma ferramenta de diferencial estratégico e competitivo.

\section{CRIAÇÃO DE UMA CULTURA DE PARTICIPAÇÃO EM PRÊMIOS DE DESIGN}

Em 2009, O Centro Brasil Design foi estabelecido como o escritório representativo do prêmio if Design Award no Brasil. Nas edições de 2013 e 2014 o número de inscritos e de premiados manteve-se quase igual ao número dos anos anteriores, o que comprova que o programa Design Excellence Brazil criou nas empresas brasileiras uma cultura de participação em prêmios internacionais de design. O trabalho do escritório representativo manteve ativa a participação das empresas brasileiras e garantiu a qualidade das inscrições, além de facilitar todo o processo de inscrição, dando suporte nas informações necessárias para as empresas se inscreverem.

Ao longo do acompanhamento de sete edições das empresas brasileiras inscrevendo-se no prêmio if, nota-se que a premiação internacional trouxe um reconhecimento expressivo para a maioria das empresas e auxiliou aquelas que tinham maior capacidade em explorar novos mercados. Sabe-se que a premiação é apenas um ingrediente de um processo complexo, mas é uma ferramenta importante de promoção e visibilidade que se utilizado pelas empresas premiadas tem grande potencial e poder de alcance.

O programa Design Excellence Brazil teve o objetivo de reconhecer a excelência da indústria brasileira no mercado internacional e difundir no país uma cultura de exportação de produtos de valor agregado. (GOUVEIA, 2001, p. 44).

Em resumo, no âmbito nacional, a divulgação dos produtos premiados contribuiu para promover o desenvolvimento da cultura da inovação pelo design, pois as empresas vencedoras despontam como casos de sucesso, o que serve de estímulo a outros empresários (FURLAN, 2006 apud CATÁLOGO..., 2006). 
Segundo GOUVEIA (2001, p.24) o design, tratado como criatividade, pode tornar-se suporte para a diversidade cultural no mundo globalizado bem como ser capaz de dotar produtos, serviços e sistemas de significados coerentes à sua própria complexidade.

Os gráficos abaixo mostram uma comparação entre os projetos premiados em 2011 e 2012 quando ainda havia o suporte financeiro do programa Design Excellence Brazil e os projetos premiados em 2013 e 2014, sem o apoio do programa. Os gráficos abrangem o recorte por categoria, porte das empresas e/ou anunciantes e localização por estado brasileiro.

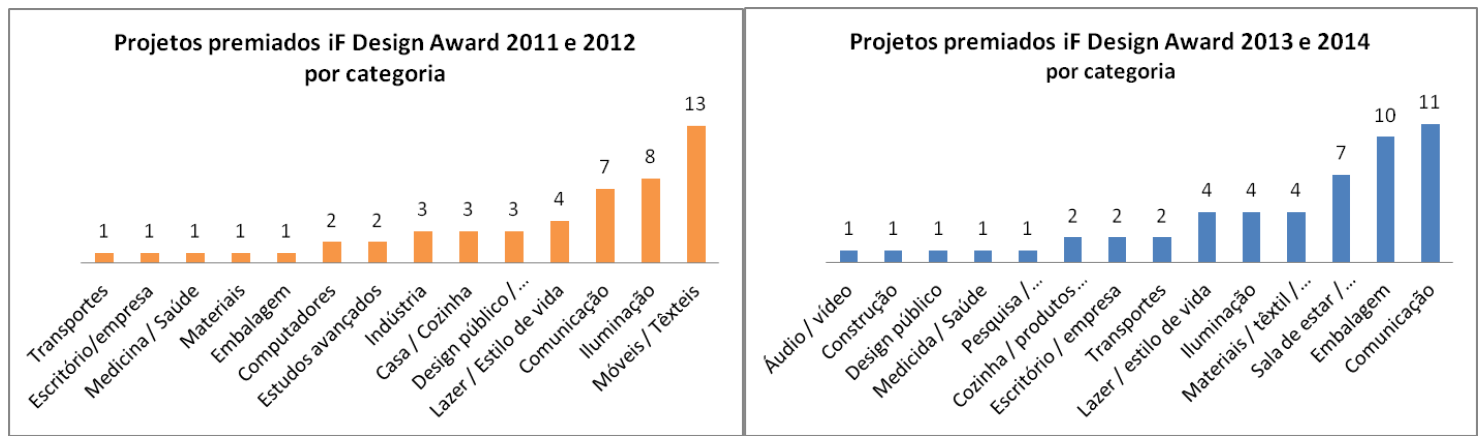

Gráfico 03: Comparação dos projetos premiados no if Design Award nos anos 2011 e 2012 versus 2013 e 2014 por categoria.

Fonte: "Elaborado pelo autor, com base na pesquisa realizada"

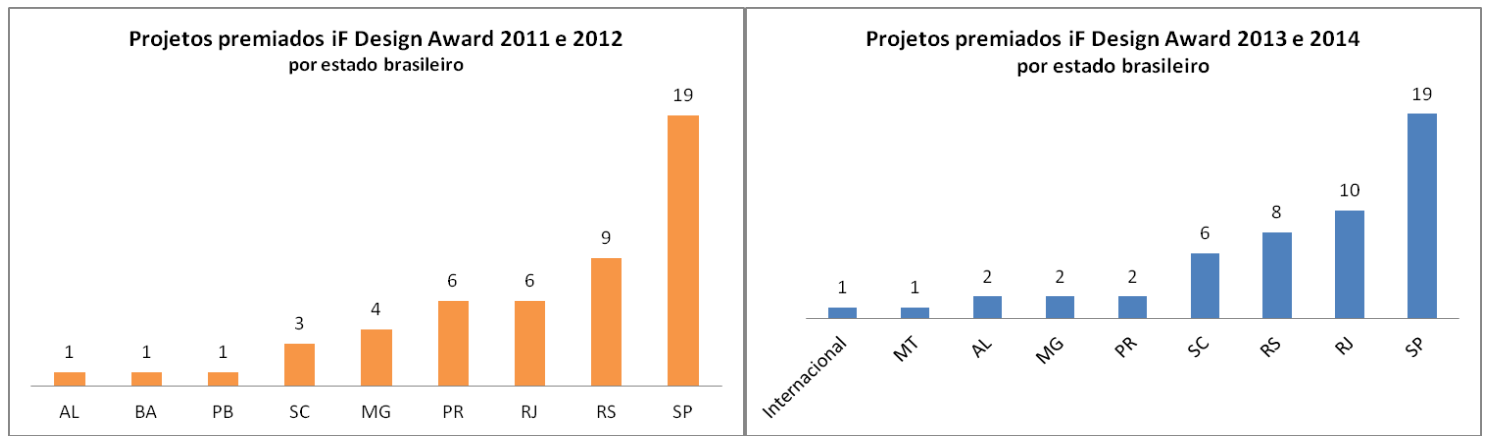

Gráfico 04: Comparação dos projetos premiados no if Design Award nos anos 2011 e 2012 versus 2013 e 2014 por estado brasileiro.

Fonte: "Elaborado pelo autor, com base na pesquisa realizada"

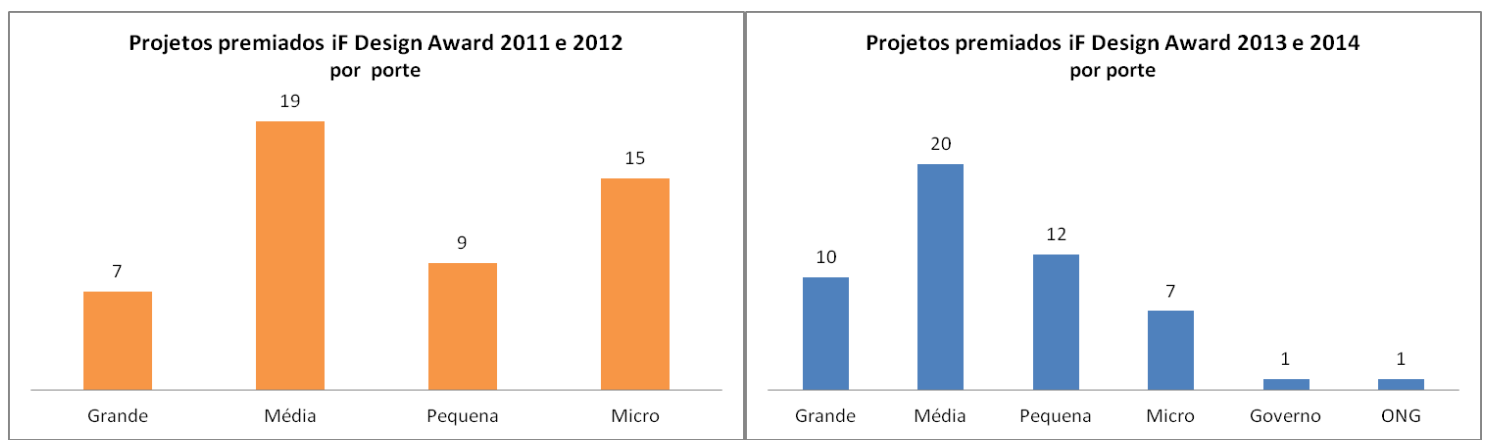

Gráfico 05: Comparação dos projetos premiados no if Design Award nos anos 2011 e 2012 versus 2013 e 2014 por porte das empresas.

Fonte: "Elaborado pelo autor, com base na pesquisa realizada"

De acordo com o gráfico 03, a categoria destaque nas edições 2011 e 2012 foi no segmento de produto (móveis e iluminação), já nas edições de 2013 e 2014 o 
destaque foi para a indústria de comunicação e embalagem. Isso aconteceu devido ao planejamento de prospecção de novos inscritos do escritório representativo do prêmio if. Nos dois últimos anos, o foco e o empenho foram para as agências de publicidade e também agências que produzem embalagens, o que resultou em um maior número de premiados nas categorias.

Se considerarmos os estados brasileiros que tiverem maior número de premiados nos últimos quatro anos estão: São Paulo, Rio de Janeiro e Rio Grande do Sul. Desta forma podemos concluir que existe um grande polo de indústrias criativas nestes estados do país.

Se considerarmos o porte das empresas premiadas, o número de micro e pequenas empresas e de empresas de médio porte ficou praticamente o mesmo. Isso mostra que empresas deste porte são as que apresentam maior capacidade de inovar pelo design, ou seja, usam o design como uma ferramenta de diferencial estratégico e competitivo.

\section{CONCLUSÃO}

Acredita-se na força da ferramenta design para gerar competitividade, qualidade e potencialidades para o país; compreendem-se os desafios encontrados para o desenvolvimento de novas abordagens em produtos (designers); identifica-se a percepção e a valorização do novo produto concebido (consumidor); e por fim, vislumbram-se ganhos competitivos que trarão reflexos para os negócios (empresas). (GOUVEIA, 2001, p.24)

A análise dos resultados da participação brasileira em um dos mais conceituados e completos prêmios de design do mundo, o if Design Award, aponta para alguns pontos positivos que merecem ser enfatizados, uma vez que há interesse das empresas em continuarem a participar, mesmo sem o apoio financeiro do programa Design Excellence Brazil.

Podemos interpretar que o programa conscientizou e educou a participação das empresas e escritórios de design no prêmio, não apenas no if, mas em diversos prêmios nacionais e internacionais de design. Mesmo sem o apoio do programa, o número de premiados brasileiros manteve-se constante. Isso mostra que o custo versus benefício proporcionado pelo prêmio é relevante para as empresas participantes. Além da chancela de um selo de excelência em design, existe todo o retorno de mídia espontânea gerada em função do prêmio e ainda toda a visibilidade e reconhecimento que o mesmo gera para as empresas e designers premiados.

Outro fator importante é a abertura para o mercado externo, uma vez que trata-se de um prêmio internacional de design, referência no mercado europeu. Além de chancelar os produtos, em termos de design e qualidade, o prêmio abre espaço para que compradores externos conheçam os produtos e entrem em contato com as empresas e designers brasileiros.

Conclui-se que os prêmios de design são de fato uma ferramenta estratégica para àquelas empresas com produtos diferenciados pelo design que procuram destaque no mercado, seja ele nacional ou internacional. Este reconhecimento vale não só pela exposição do produto e da marca da empresa em um ambiente seleto, mas também pelas portas que se abrem no mercado externo. 


\section{REFERÊNCIAS}

A comparative look at design competitions. if International Forum Design, 2006. Disponível na internet por http em:

<http://www.ifdesign.de/cmsmdblive/582.pdf >.Acesso em 27 mar. 2014

BAXTER, M. Projeto de produto: guia prático para o desenvolvimento de novos produtos. São Paulo: Edgard Blücher 1998. 261p.

BORGES, A. Prêmio design: 1986-1996. São Paulo: Museu da Casa Brasileira, 1996.

GOUVEIA, Ana. Os ganhos competitivos das empresas brasileiras vencedoras no prêmio internacional if Product Design Award. 2011. 124 f. Tese (Mestrado). FAE Centro Universitário, curso de Organizações e Desenvolvimento.

CATÁLOGO DESIGN EXCELLENCE BRAZIL: 2003 - 2006. São Paulo: APEX-Brasil, 2006. FERRAZ, J. C; KUPFER, D.; HAGUENAUER, L. Made in Brazil: desafios competitivos para a indústria. Rio de Janeiro: Campus, 1995.

Focusing on design boosts sales. German Design Council, 2012. Disponível na

internet por http em: <http://www.german-design-
council.de/fileadmin/Bilder/Pressebereich/Focusing_on_design.pdf $>$. Acesso em 26 mar. 2014

FONTOURA, I. Salão design: uma visão do design moveleiro latino-americano - dez edições, dezoito anos. In: SALÃO DESIGN MOVELSUL, Bento Gonçalves, 2006

MORAES, D. Limites do design. São Paulo: Studio Nobel, 1999.

MOZOTA, B. B.; KLOPSH, C.; COSTA, F. C. X. Gestão do design: usando o design para construir valor de marca e inovação corporativa. Porto Alegre: Bookman, 2011.

MANZINI, E.; VEZZOLI, C. O desenvolvimento de produtos sustentáveis. São Paulo: Editora da Universidade, 2002.

PORTAL KIA. Disponível na internet por http em: http://www.kia.com/worldwide/. Acesso em 10 abr. 2014. 